\title{
Ketoacidosis, Hypertriglyceridemia and Acute Pancreatitis Induced by Soft Drink Polydipsia in a Patient with Occult Central Diabetes Insipidus
}

\author{
Yasutaka Tsujimoto ${ }^{1}$, Tomoaki Nakamura ${ }^{1}$, Jun Onishi ${ }^{2}$, Naoto Ishimaru ${ }^{2}$, Naoko Iwata ${ }^{3,4}$, \\ Haruki Fujisawa ${ }^{4}$, Atsushi Suzuki ${ }^{4}$, Yoshihisa Sugimura ${ }^{4}$ and Kazuo Chihara ${ }^{1}$
}

\begin{abstract}
:
A 21-year-old Japanese man without known diabetes mellitus had abdominal pain. The diagnosis was ketoacidosis and hypertriglyceridemia-induced acute pancreatitis. He had polydipsia and polyuria and had habitually drunk several soft drinks every day for two years. After hospitalization, despite adequate liquid intake, dehydration remained with hypotonic polyuria. Further examinations revealed the coexistence of central diabetes insipidus (CDI), possibly caused by lymphocytic infundibulo-neurohypophysitis, based on antirabphilin-3A antibody positivity. Although CDI had been undiagnosed for two years, over-consumption of sugar-rich soft drinks to ease thirst caused ketoacidosis, hypertriglyceridemia, and acute pancreatitis. There are no previous reports of this three-part combination of symptoms caused by CDI.
\end{abstract}

Key words: ketoacidosis, soft drink ketosis, acute pancreatitis, central diabetes insipidus, lymphocytic infundibulo-neurohypophysitis, anti-rabphilin-3A antibody

(Intern Med Advance Publication)

(DOI: 10.2169/internalmedicine.7663-21)

\section{Introduction}

Diabetic ketoacidosis (DKA) is a severe, life-threatening syndrome. It comprises hyperglycemia, ketosis, and acidosis resulting from relative or absolute insulin deficiency, together with an increase in circulating concentrations of counterregulatory hormones $(1,2)$. DKA is typically caused by either inappropriate insulin consumption or by infection. Other causes include a new onset of diabetes and drug or alcohol abuse $(3,4)$. The frequent intake of large amounts of sugar-enriched soft drinks is also known to cause DKA, known as 'soft drink ketosis', in patients with diabetes and even in those with pre-diabetes. Soft drink ketosis is more common in Asian patients than in Western patients and is most common in obese patients and men (5-7). It probably results in a vicious cycle of thirst and soft drink intake, leading to glucose toxicity (5).
Central diabetes insipidus (CDI) manifests as polyuria, thirst, and polydipsia due to impaired vasopressin secretion from the posterior pituitary $(8,9)$. Although clarification of the underlying diseases causing CDI is crucial for the prognosis, the most common causes of CDI are idiopathic (8-10). Accumulating evidence has shown that a moderate proportion of idiopathic CDI might result from lymphocytic infundibulo-neurohypophysitis (LINH) (11). Anti-rabphilin-3A antibodies are found in the majority of patients with LINH (12). Coexistence of CDI and DKA is rare, with only few published reports, and the causal relationship has not yet been addressed (13-17).

We herein report an instructive case that demonstrates that CDI can be a hidden cause of soft drink ketosis, hypertriglyceridemia, and acute pancreatitis.

\footnotetext{
${ }^{1}$ Department of Diabetes and Endocrinology, Akashi Medical Center Hospital, Japan, ${ }^{2}$ Department of General Internal Medicine, Akashi Medical Center Hospital, Japan, ${ }^{3}$ Department of Endocrinology and Diabetes, Daido Hospital, Japan and ${ }^{4}$ Department of Endocrinology, Diabetes and Metabolism, Fujita Health University, Japan

Received: March 30, 2021; Accepted: June 25, 2021; Advance Publication by J-STAGE: August 6, 2021

Correspondence to Dr. Yasutaka Tsujimoto, yasutsuji66@gmail.com
} 
Table 1. Patient's Laboratory Findings.

\begin{tabular}{|c|c|c|}
\hline Variable & Result & Reference range \\
\hline \multicolumn{3}{|l|}{ Blood } \\
\hline White-cell count $(/ \mu \mathrm{L})$ & 20,860 & $4,500-8,000$ \\
\hline Neutrophils (\%) & 86 & $40-70$ \\
\hline Eosinophils (\%) & 0.0 & $0.0-7.0$ \\
\hline Basophils (\%) & 0.0 & $0.0-1.0$ \\
\hline Monocytes (\%) & 8.0 & $2.0-7.0$ \\
\hline Lymphocytes (\%) & 6.0 & $27-47$ \\
\hline Hemoglobin (g/dL) & 19.9 & $13-17$ \\
\hline Hematocrit $(\%)$ & 64.6 & $45-55$ \\
\hline Platelet count $(/ \mu \mathrm{L})$ & 390,000 & $100,000-330,000$ \\
\hline Total protein $(\mathrm{g} / \mathrm{dL})$ & 7.4 & $6.3-8.2$ \\
\hline Albumin (g/dL) & 5.3 & $3.5-5.0$ \\
\hline Urea nitrogen (mg/dL) & 37.5 & $8.0-20.0$ \\
\hline Creatinine (mg/dL) & 2.09 & $0.5-1.2$ \\
\hline Sodium $(\mathrm{mEq} / \mathrm{L})$ & 134 & $135-147$ \\
\hline Potassium (mEq/L) & 4.8 & $3.3-4.8$ \\
\hline Chloride (mEq/L) & 91 & 98-108 \\
\hline Aspartate aminotransferase (U/L) & 293 & $8-38$ \\
\hline Alanine aminotransferase (U/L) & 478 & $4-44$ \\
\hline Lactate dehydrogenase (U/L) & 562 & $106-211$ \\
\hline Alkaline phosphatase (U/L) & 864 & $104-338$ \\
\hline$\gamma$-glutamyl transpeptidase (U/L) & 695 & $16-73$ \\
\hline Amylase (IU/L) & 2,881 & $40-130$ \\
\hline Lipase (U/L) & 10,480 & $13-42$ \\
\hline Glucose (mg/dL) & 1537 & $65-110$ \\
\hline $\operatorname{HbA1c}(\%)$ & 13.0 & 4.6-6.2 \\
\hline Serum osmolality $\left(\mathrm{mOsm} / \mathrm{kg} \mathrm{H}_{2} \mathrm{O}\right)$ & 392 & $274-290$ \\
\hline HDL-C (mg/dL) & 45 & $40-86$ \\
\hline LDL-C (mg/dL) & 130 & $0-140$ \\
\hline Triglyceride (mg/dL) & 1,037 & $60-140$ \\
\hline Acetoacetic acid $(\mu \mathrm{mol} / \mathrm{L})$ & 2,432 & $0-55$ \\
\hline Beta-hydroxybutyric acid ( $\mu \mathrm{mol} / \mathrm{L})$ & 6,773 & $0-85$ \\
\hline C-reactive protein $(\mathrm{mg} / \mathrm{dL})$ & 3.1 & $0-0.30$ \\
\hline $\mathrm{pH}$ & 7.190 & $7.35-7.45$ \\
\hline $\mathrm{CO} 2-(\mathrm{mmHg})$ & 28.9 & $35-48$ \\
\hline $\mathrm{HCO} 3-(\mathrm{mmol} / \mathrm{L})$ & 11 & $23-28$ \\
\hline Base Excess (mmol/L) & -15.4 & $-2.2-1.2$ \\
\hline \multicolumn{3}{|l|}{ Urine } \\
\hline Urine glucose & $4+$ & negative \\
\hline Urine ketone & $3+$ & negative \\
\hline Urine osmolality $\left(\mathrm{mOsm} / \mathrm{kg} \mathrm{H} \mathrm{H}_{2} \mathrm{O}\right.$ ) & 424 & $49-1,300$ \\
\hline Urine sodium $(\mathrm{mEq} / \mathrm{L})$ & 6 & \\
\hline Urine potassium $(\mathrm{mEq} / \mathrm{L})$ & 8.9 & \\
\hline Urine chloride (mEq/L) & 10 & \\
\hline
\end{tabular}

\section{Case Presentation}

A 21-year-old Japanese man developed a gradual onset of general fatigue and appetite loss for 3 weeks. He presented to the emergency department with severe abdominal pain. His medical history was unremarkable, and there was no family history of diabetes mellitus or endocrine disorders. He had no regular medications and did not drink alcohol or smoke. However, his family reported that he had been living alone for the past three years and had an unhealthy diet; furthermore, he had been conscious of polydipsia and polyuria and habitually drank several bottles of soft drinks on a daily basis for about two years. The results of his medical checkups 3 years before admission were completely normal: $\mathrm{HbA}$ 1c $5.4 \%$, fasting plasma glucose $92 \mathrm{mg} / \mathrm{dl}$, serum triglyceride $74 \mathrm{mg} / \mathrm{dl}$ and body mass index $17.4 \mathrm{~kg} / \mathrm{m}^{2}$.

On an examination in the emergency department, the patient was restless and groaning in pain. His blood pressure was $87 / 52 \mathrm{mmHg}$, pulse rate $105 / \mathrm{min}$, and respiratory rate $28 /$ min. His body temperature was $36.3{ }^{\circ} \mathrm{C}$, his height was $171 \mathrm{~cm}$, his body weight was $74 \mathrm{~kg}$, and his body mass index was $25.3 \mathrm{~kg} / \mathrm{m}^{2}$. His Glasgow coma scale was E3V4M5. An examination of the oropharynx showed that his mucous membranes were dry. His neck was supple. A cardiovascular examination was normal, except for tachycardia, and his lungs were clear on auscultation. An abdominal examination showed diffuse tenderness without muscular defense. He had dry skin but no rash or edema. Neurologically, he was asymptomatic except for restlessness.

On admission, an initial blood investigation revealed serum amylase 2,881 U/L, serum lipase 10,480 U/L, plasma glucose $1,537 \mathrm{mg} / \mathrm{dL}, \mathrm{HbA} 1 \mathrm{c} 13.0 \%$, triglyceride $1,037 \mathrm{mg} /$ $\mathrm{dL}$, acetoacetic acid 2,432 $\mu \mathrm{mol} / \mathrm{L}$, beta-hydroxybutyric acid $6,773 \mu \mathrm{mol} / \mathrm{L}$, and plasma osmolality $392 \mathrm{mOsm} / \mathrm{kg} \mathrm{H}_{2} \mathrm{O}$. A urinalysis was positive for urinary glucose and ketones, and urine osmolality was $424 \mathrm{mOsm} / \mathrm{kg} \mathrm{H}_{2} \mathrm{O}$. An arterial blood gas analysis showed $\mathrm{pH} 7.190, \mathrm{CO}_{2} 28.9 \mathrm{mmHg}, \mathrm{HCO}_{3-}-11$ $\mathrm{mmol} / \mathrm{L}$, base excess $-15.4 \mathrm{mmol} / \mathrm{L}$. Glutamic acid decarboxylase antibody and IA-2 antibody were undetectable. Glutamic acid decarboxylase antibody and IA-2 antibody were measured by an enzyme-linked immunosorbent assay (ELISA; RSR Limited, Cardiff, United Kingdom). The reference range of glutamic acid decarboxylase antibodies is below $5.0 \mathrm{U} / \mathrm{mL}$, that of IA-2 antibody is below $0.6 \mathrm{U} / \mathrm{mL}$. We considered this to be indicative of DKA and acute pancreatitis. Other findings are shown in Table 1. Non-contrast CT of the abdomen confirmed a diffuse enlargement of the pancreas, which was surrounded by clouded, dense fatty tissue (Fig. 1a)). The diagnosis was DKA and acute pancreatitis due to hypertriglyceridemia.

The patient was transferred to the intensive-care unit and treated with intravenous extracellular fluids, continuous intravenous insulin, analgesics, sedatives, and vasopressors and was aided by a ventilator. By the third day of hospitalization, his hyperglycemia and ketoacidosis had improved, but his dehydration remained and resulted in hypotension and the use of noradrenaline (Fig. 2A). On day 3, before the use of intravenous vasopressin, a large amount of dilute urine (urine volume, approximately $5,900 \mathrm{ml} /$ day; urine osmolality, approximately $200 \mathrm{mOsm} / \mathrm{kg} \quad \mathrm{H}_{2} \mathrm{O}$ ) was excreted (Fig. 2A). At that time, serum sodium was increased to 172 $\mathrm{mEq} / \mathrm{L}$, and his plasma osmolality was $362 \mathrm{mOsm} / \mathrm{kg} \mathrm{H}_{2} \mathrm{O}$. The simultaneously measured plasma arginine vasopressin (AVP) concentration was $1.0 \mathrm{pg} / \mathrm{mL}$. AVP was measured by a radioimmunoassay (RIA; YAMASA, Tokyo, Japan). Cen- 

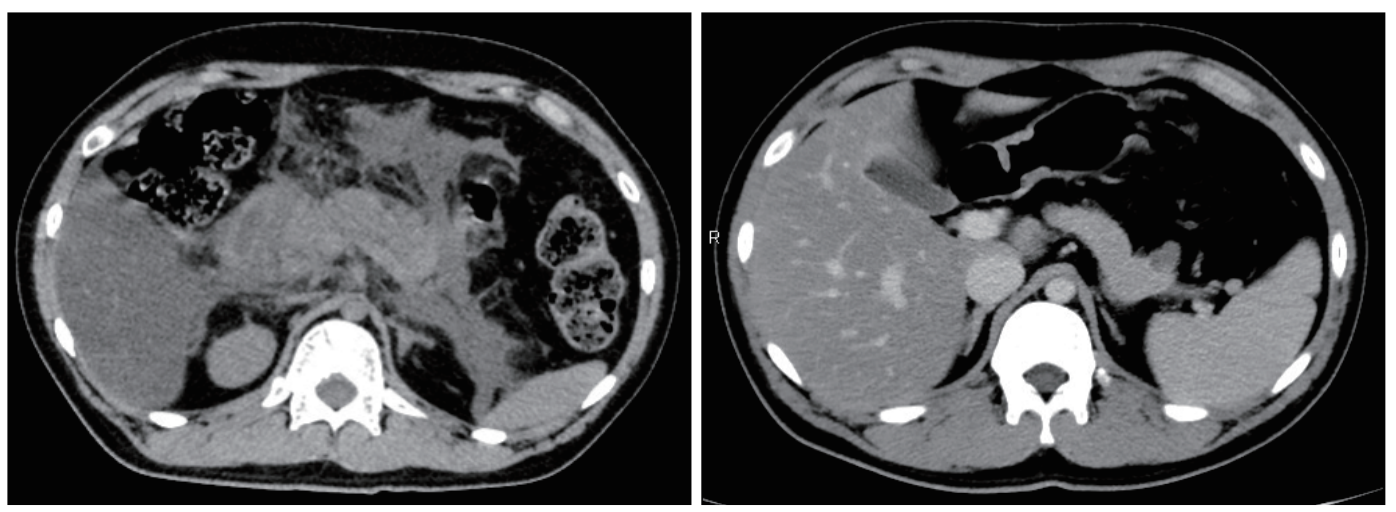

Figure 1. (a) Abdominal CT before treatment without contrast material. Diffusely enlarged pancreas and clouded fatty tissue density around the pancreas were typical features of acute pancreatitis. (b) Abdominal CT after treatment with contrast materials. Pseudo-pancreatic cysts were left after amelioration of pancreatitis.
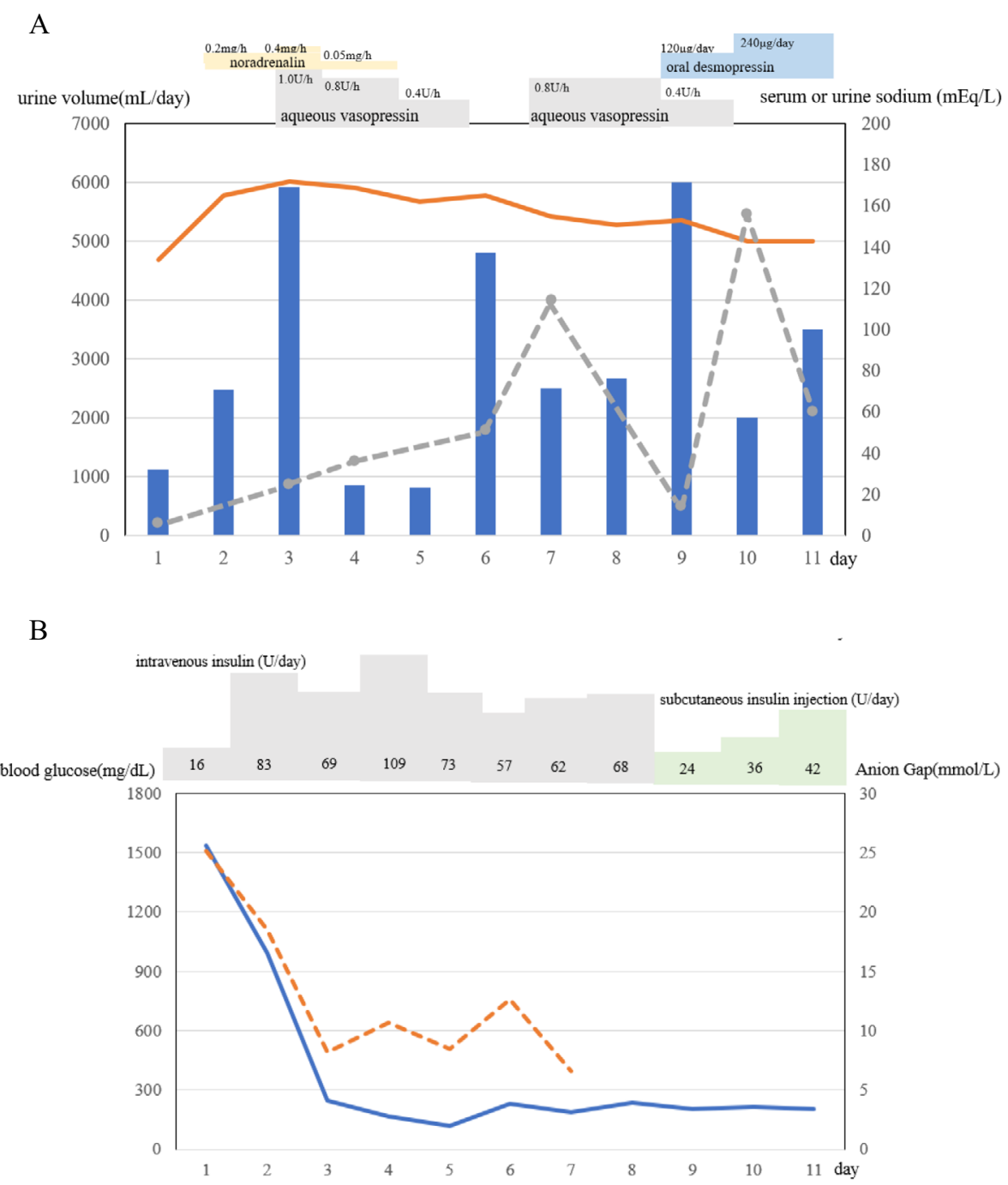

Figure 2. Clinical course. A) The bar graphs show the urine volume (mL/day). Solid and dotted lines show the serum sodium levels $(\mathrm{mEq} / \mathrm{L})$ and urine sodium levels $(\mathrm{mEq} / \mathrm{L})$, respectively. Administered drugs and their doses are shown in squares. B) Solid and dotted lines show the blood glucose $(\mathrm{mg} / \mathrm{dL})$ and anion gap $(\mathrm{mmol} / \mathrm{L})$, respectively. Administered drugs and their doses are shown in squares. 


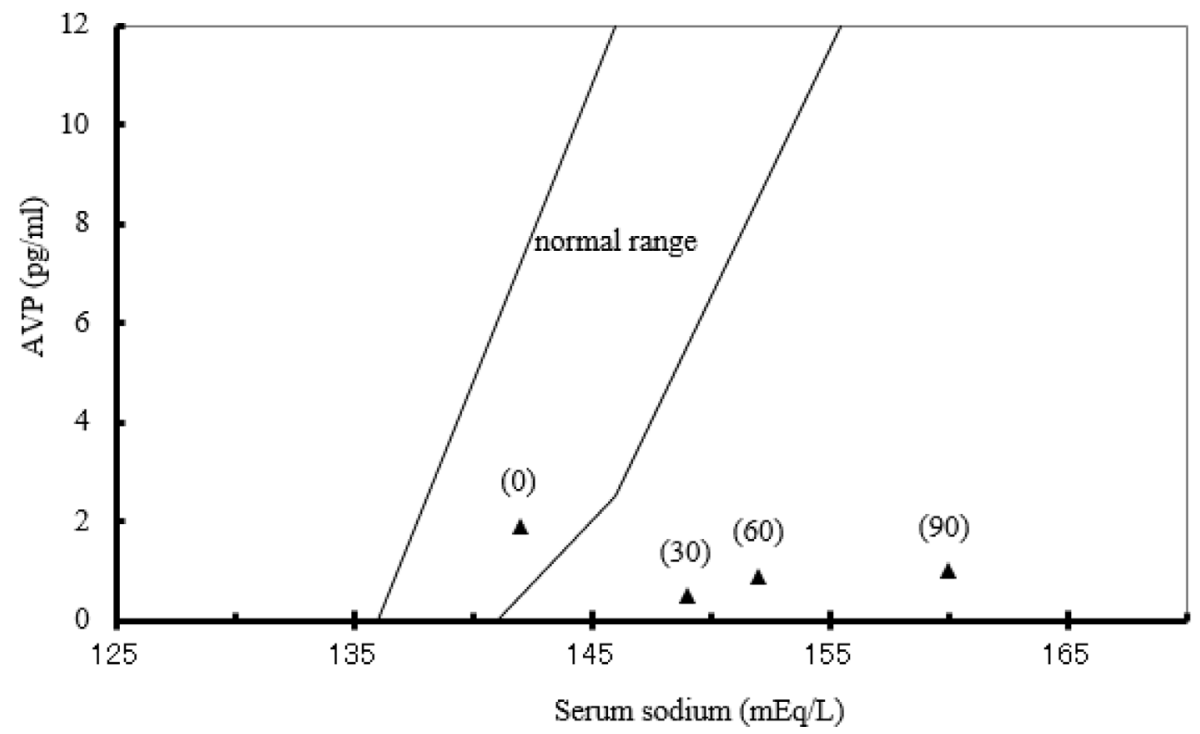

Figure 3. The correlation between plasma AVP and serum sodium in the $5 \%$ hypertonic saline test. The dots are the 0-, 30-, 60-, and 90-minute values, as shown in parentheses. The gradient factor for the simple regression was $\mathbf{- 0 . 0 4}$.

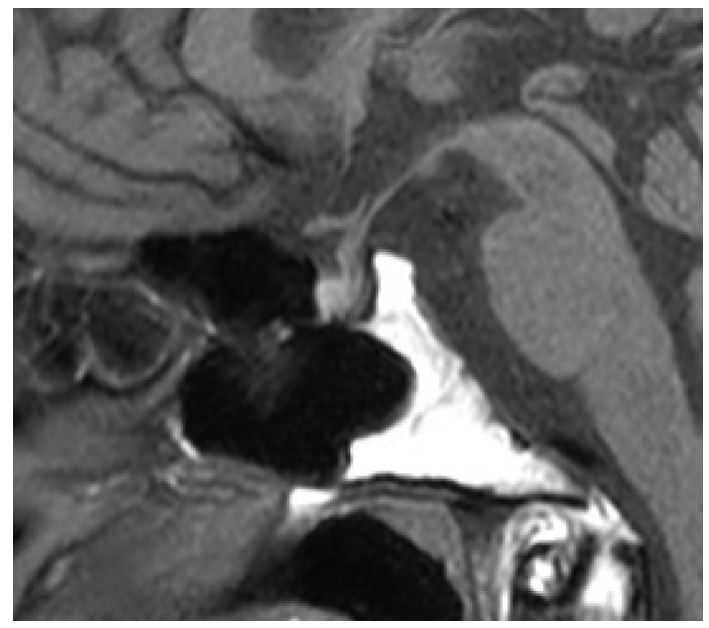

Figure 4. Findings of magnetic resonance imaging (MRI) T1-weighted imaging (T1WI) of the sagittal section of the pituitary gland. There was no high-intensity signal in the posterior lobe with mild enlargement of the pituitary stalk.

tral diabetes insipidus (CDI) was suspected because of hypotonic polyuria and severe dehydration. After intravenous vasopressin was administered, the patient's polyuria dramatically improved. Thereafter, dehydration and hypernatremia improved, and intravenous vasopressin was subsequently replaced with oral desmopressin. He was transferred to the general ward on the $11^{\text {th }}$ day (Fig. 2A).Fig. 2B shows the course of insulin treatment and changes in blood glucose and anion gap.

Detailed endocrinological examinations were carried out to confirm the diagnosis. The $5 \%$ hypertonic saline test showed no marked increase in the plasma AVP concentration with the increased serum sodium level and plasma osmolality (Fig. 3). A regression analysis of plasma AVP and serum sodium concentrations revealed a gradient factor of 0.04. This met the criteria for a diagnosis of CDI, in which the cut-off value is $<0.1$ to discriminate from other entities (18). Aqueous vasopressin (5 units, subcutaneously) increased the urine osmolality to $653 \mathrm{mOsm} / \mathrm{kg} \mathrm{H} \mathrm{H}_{2} \mathrm{O}$ and decreased the 120-min urine volume. Plain T1-weighted pituitary magnetic resonance imaging showed loss of the highintensity signal in the posterior lobe and mild enlargement of the pituitary stalk without a pituitary tumor (Fig. 4). A simultaneous stimulation test by corticotropin-releasing hormone, thyrotropin-releasing hormone, luteinizing hormonereleasing hormone, and growth hormone-releasing peptide-2 showed that the patient's anterior pituitary function remained normal (Table 2). These findings were all compatible with a diagnosis of CDI, but the precise etiology of CDI remained unclear, as serum angiotensin-converting enzyme, antineutrophil cytoplasmic antibody, IgG4, $\beta$-human chorionic gonadotropin and $\alpha$-fetoprotein levels were within the reference values, and the interferon-gamma release assay was negative (Table 2). With the patient's informed consent, we then measured anti-rabphilin-3A antibody in his serum, which was recently found to be a highly sensitive and reliable marker of LINH (12). Anti-rabphilin-3A antibody was positive in his serum according to Western blotting, indicating a high possibility that the cause of his CDI was LINH. The serum labeled as a positive control was that of a case previously diagnosed with LINH as a result of a biopsy and reported by us (Fig. 5)) (19), and the serum labeled as a negative control was that of a case of CDI after surgery for craniopharyngioma (Fig. 5).

After being transferred to the general ward, the patient was advised not to consume soft drinks, and the daily doses of subcutaneously injected insulin were gradually reduced while his plasma glucose was monitored. Three weeks after 
Table 2. Endocrinological Findings and Others.

\begin{tabular}{|c|c|c|}
\hline Variable & & Result \\
\hline \multicolumn{3}{|c|}{ TRH-CRH-LHRH-GHRP2 test } \\
\hline \multirow[t]{5}{*}{$\mathrm{TSH}(\mu \mathrm{IU} / \mathrm{mL})$} & 0 minute & 1.390 \\
\hline & 30 minutes & 5.990 \\
\hline & 60 minutes & 3.600 \\
\hline & 90 minutes & 2.480 \\
\hline & 120 minutes & 1.790 \\
\hline \multirow[t]{5}{*}{ PRL (ng/mL) } & 0 minute & 18.5 \\
\hline & 30 minutes & 48.4 \\
\hline & 60 minutes & 25.7 \\
\hline & 90 minutes & 21.3 \\
\hline & 120 minutes & 20.4 \\
\hline \multirow[t]{5}{*}{$\mathrm{ACTH}(\mathrm{pg} / \mathrm{mL})$} & 0 minute & 8.2 \\
\hline & 30 minutes & 46.0 \\
\hline & 60 minutes & 27.2 \\
\hline & 90 minutes & 15.2 \\
\hline & 120 minutes & 11.9 \\
\hline \multirow[t]{5}{*}{ cortisol $(\mu \mathrm{g} / \mathrm{dL})$} & 0 minute & 12.00 \\
\hline & 30 minutes & 17.70 \\
\hline & 60 minutes & 13.42 \\
\hline & 90 minutes & 9.84 \\
\hline & 120 minutes & 7.83 \\
\hline \multirow[t]{5}{*}{$\mathrm{LH}(\mu \mathrm{IU} / \mathrm{mL})$} & 0 minute & 5.8 \\
\hline & 30 minutes & 21.0 \\
\hline & 60 minutes & 14.4 \\
\hline & 90 minutes & 12.4 \\
\hline & 120 minutes & 11.2 \\
\hline \multirow[t]{5}{*}{ FSH $(\mu \mathrm{IU} / \mathrm{mL})$} & 0 minute & 5.1 \\
\hline & 30 minutes & 8.4 \\
\hline & 60 minutes & 8.2 \\
\hline & 90 minutes & 7.8 \\
\hline & 120 minutes & 7.4 \\
\hline \multirow[t]{5}{*}{ GH (ng/mL) } & 0 minute & 2.03 \\
\hline & 15 minutes & 16.80 \\
\hline & 30 minutes & 15.50 \\
\hline & 45 minutes & 5.80 \\
\hline & 60 minutes & 4.91 \\
\hline \multicolumn{3}{|l|}{ Other findings } \\
\hline ACE (U/L) & & 7.9 \\
\hline ANCA (U/mL) & & undetectable \\
\hline IgG4 (mg/dL) & & 47.9 \\
\hline$\beta-\mathrm{HCG}(\mathrm{ng} / \mathrm{mL})$ & & undetectable \\
\hline $\operatorname{AFP}(n g / m L)$ & & 2.7 \\
\hline IGRA & & negative \\
\hline
\end{tabular}

TRH: thyrotropin-releasing hormone, CRH: corticotropin-releasing hormone, LHRH: luteinizing hormone-releasing hormone, GHRP2: growth hormone-releasing peptide-2, TSH: thyroid-stimulating hormone, PRL: prolactin, ACTH: adrenocorticotropic hormone, LH: luteinizing hormone, FSH: follicle-stimulating hormone, GH: growth hormone, ACE: angiotensin-converting enzyme, ANCA: anti-neutrophil cytoplasmic antibody, $\beta$-HCG: $\beta$-human chorionic gonadotropin, AFP: $\alpha$-fetoprotein, IGRA: interferon-gamma release assay

his hospitalization, after his polyuria and stomachache had completely improved, he was discharged. On discharge, he injected himself with insulin degludec at 18 units and insulin lispro at 14 units each day and took 2 tablets of oral des- mopressin $120 \mu \mathrm{g}$. Three months after his discharge, his HbA1c value had decreased to $5.3 \%$, so insulin therapy was ceased and switched to dietary therapy combined with exercise therapy. A 75-g oral glucose tolerance test (75-g OGTT) performed around this time showed that fasting glucose was $116 \mathrm{mg} / \mathrm{dL}$, and the glucose value was $200 \mathrm{mg} / \mathrm{dL}$ at $120 \mathrm{~min}$, but the insulinogenic index was 1.1 , indicating obvious improvement of endogenous insulin secretory potency. There was no evidence suggesting sustained acute pancreatitis, but pseudo-pancreatic cysts were shown on abdominal CT (Fig. 1b). The patient has been receiving daily supplementation of 2 tablets of oral desmopressin $120 \mu \mathrm{g}$.

\section{Discussion}

We reported a young Japanese man without diabetes mellitus in which a tremendous intake of sugar-enriched soft drinks for at least two years to ease severe thirst caused the dangerous combination of ketoacidosis, hypertriglyceridemia, and acute pancreatitis. Ketoacidosis due to sugarenriched soft drink consumption, so-called 'soft drink ketosis', has been reported sporadically in obese Asian men with diabetes as well as in those with pre-diabetes (5-7). Reports of soft drink ketosis in other ethnic groups, such as Caucasians, are extremely rare (20). The mechanism underlying the differences in incidence among ethnic groups require elucidation, although the endogenous insulin secretory potential may be naturally lower in Asians than in Caucasians. In addition, our patient developed necrotizing pancreatitis caused by hypertriglyceridemia. Acute pancreatitis can also be an exacerbation factor of ketoacidosis as it can result in transient insulin deficiency due to beta-cell dysfunction and may also increase insulin resistance due to systemic inflammation (21). In the present case, severe thirst derived from occult undiagnosed CDI was an important trigger for the illness, at least during the early period of his disease.

CDI is caused by impaired AVP secretion from the pituitary gland and is characterized by hypotonic polyuria, thirst, and polydipsia $(8,9)$. The most common cause of CDI is idiopathic, followed by tumors, infiltrative diseases, neurosurgery, trauma, and rare genetic abnormality $(8,9)$. Although the mechanism underlying idiopathic CDI has not been fully elucidated, an autoimmune process is suggested to be involved in some patients with idiopathic CDI (22-24). Hypophysitis is histologically classified into lymphocytic, granulomatous, xanthomatous, IgG4-related, or necrotizing forms, among which more than $70 \%$ are lymphocytic (25). Lymphocytic hypophysitis, a chronic inflammatory form with varying degrees of pituitary dysfunction, is classified by the affected location of the pituitary, lymphocytic adenohypophysitis, lymphocytic infundibulo-neurohypophysitis (LINH), and lymphocytic pan-hypophysitis (11). Although LINH does not generally result in hypopituitarism, it causes CDI and swelling of the posterior pituitary and/or pituitary stalk. To definitively diagnose hypophysitis, a histological examination of specimens obtained by a transsphenoidal pi- 


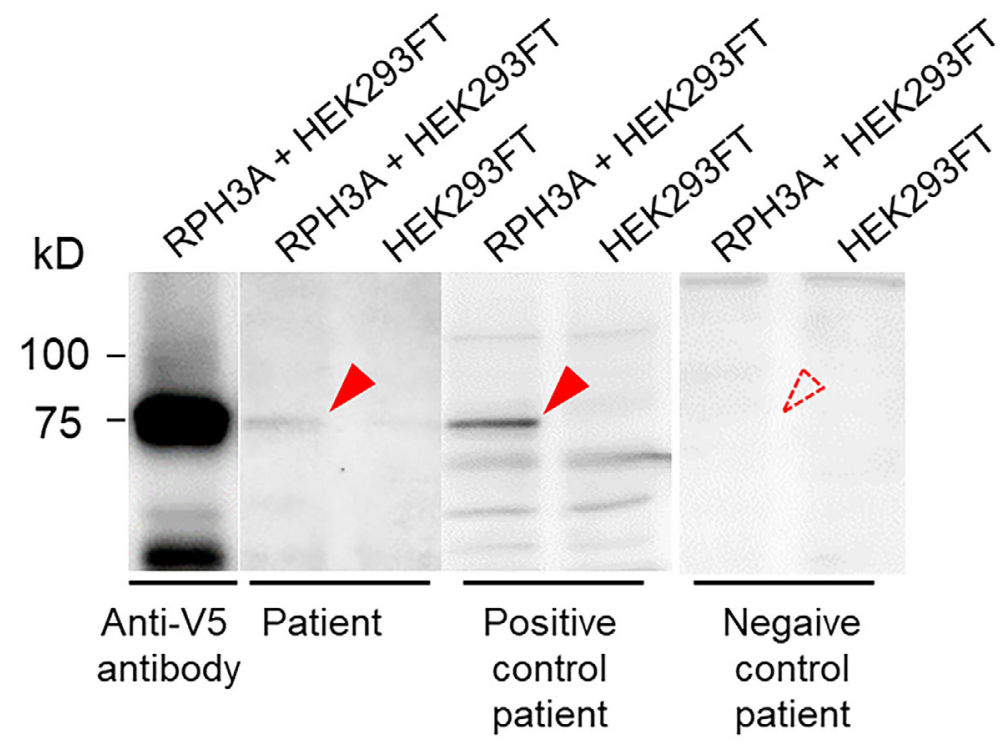

Figure 5. Detection of anti-rabphilin-3A antibodies by Western blotting. Recombinant full-length human rabphilin-3A expressed in HEK293FT cells (RPH3A+HEK293FT, left lanes) or control cell lysate from HEK293FT (HEK293FT, right lanes) was probed with serum from the present patient (patient), from a patient who had been diagnosed with LINH previously (positive control patient), or from a patient who had been diagnosed with craniopharyngioma previously (negative control patient). The arrowhead indicates the presence of anti-rabphilin-3A antibodies. The dashed arrowhead indicates the absence of anti-rabphilin-3A antibodies. Recombinant full-length human rabphilin-3A expressed in HEK293FT cells was also probed with an anti-V5 antibody as a positive control (Anti-V5 antibody) in the first lane from the left.

tuitary open biopsy is necessary, although it is sometimes difficult to obtain consent from the patient for this if the purpose is only to confirm a diagnosis.

Autoantibodies to rabphilin-3A were recently reported by Sugimura et al. in the majority of their patients with LINH, and they suggested that measurement of the antibody may be diagnostically useful (12). Anti-rabphilin-3A antibodies were detected in 22 of their $29(76 \%)$ patients (including all 4 of the biopsy-proven samples) with LINH. In contrast, the antibodies were absent in patients with biopsy-proven sellar/ suprasellar masses without lymphocytic hypophysitis ( $\mathrm{n}=$ 34), including 18 patients with CDI. Rabphilin-3A, which regulates secretory vesicle trafficking, is expressed in posterior pituitary and hypothalamic vasopressin neurons but not anterior pituitary neurons. Rabphilin-3A is suggested to be a pathogenic antigen, and $\mathrm{T}$ cells specific for rabphilin-3A are involved in the pathogenesis of LINH according to experiments with mice immunized with rabphilin-3A (26). In the present case, anti-rabphilin-3A antibodies were positive, so the patient was able to be clinically diagnosed with LINH without the need for an invasive pituitary biopsy.

CDI combined with DKA has been highlighted in only a small number of case reports (13-17). If both occur at the same time, it may be difficult to make a precise diagnosis, which can pose a serious threat to a patient's life. Fortunately, in the current case, we noticed the probable coexistence of CDI during intensive treatment for severe ketoacidosis and pancreatitis, thereby leading to a complete cure.
To our knowledge, this is the first case report to describe the three-part combination of ketoacidosis, hypertriglyceridemia, and acute pancreatitis associated with soft drink abuse caused by CDI due to LINH. In the present case, thirst and heavy consumption of soft drinks had been present for about two years, and the symptoms were initially thought to be those of diabetes but were actually symptoms of CDI. Notably, the medical history was unremarkable, and after discharge, the patient had only mild glucose intolerance with medical nutrition therapy.

In conclusion, CDI might be a cause of not only soft drink abuse but also the life-threatening induction of a threepart combination of severe ketoacidosis, hypertriglyceridemia, and acute pancreatitis.

The authors state that they have no Conflict of Interest (COI).

\section{References}

1. Kitabchi AE, Umpierrez GE, Miles JM, Fisher JN. Hyperglycemic crises in adult patients with diabetes. Diabetes Care 32: 13351343, 2009.

2. Nyenwe EA, Kitabchi AE. The evolution of diabetic ketoacidosis: An update of its etiology, pathogenesis and management. Metabolism 65: 507-521, 2016.

3. Dhatariya K, Nunney I, Iceton G. Institutional factors in the management of adults with diabetic ketoacidosis in the UK: results of a national survey. Diabet Med 33: 269-270, 2016.

4. Dhatariya KK, Nunney I, Higgins K, Sampson MJ, Iceton G. Na- 
tional survey of the management of Diabetic Ketoacidosis (DKA) in the UK in 2014. Diabet Med 33: 252-260, 2016.

5. Yamada K, Nonaka K. Diabetic ketoacidosis in young obese Japanese men. Diabetes Care 19: 671, 1996.

6. Nagasaka S, Ishikawa $S$, Itabashi $N$, Rokkaku K, Saito $T$. Ketoacidosis-onset type 2 diabetes in Japanese. Association with the widespread distribution of soft drinks and vending machines. Diabetes Care 21: 1376-1378, 1998.

7. Tanaka K, Moriya T, Kanamori A, Yajima Y. Analysis and a longterm follow up of ketosis-onset Japanese NIDDM patients. Diabetes Res Clin Pract 44: 137-146, 1999.

8. Arima H, Azuma Y, Morishita Y, Hagiwara D. Central diabetes insipidus. Nagoya J Med Sci 78: 349-358, 2016.

9. Garrahy A, Moran C, Thompson CJ. Diagnosis and management of central diabetes insipidus in adults. Clin Endocrinol 90: 23-30, 2019.

10. Di Iorgi N, Allegri AEM, Napoli F, et al. Central diabetes insipidus in children and young adults: etiological diagnosis and long-term outcome of idiopathic cases. J Clin Endocrinol Metab 99: 1264-1272, 2014

11. Takagi H, Iwama S, Sugimura Y, et al. Diagnosis and treatment of autoimmune and IgG4-related hypophysitis: clinical guidelines of the Japan Endocrine Society. Endocr J 67: 373-378, 2020.

12. Iwama S, Sugimura $Y$, Kiyota A, et al. Rabphilin-3A as a Targeted Autoantigen in Lymphocytic Infundibulo-neurohypophysitis. J Clin Endocrinol Metab 100: E946-E954, 2015.

13. Taubin H, Matz R. Cerebral edema, diabetes insipidus, and sudden death during the treatment of diabetic ketoacidosis. Diabetes $\mathbf{1 7}$ 108-109, 1968

14. Mitsukawa T, Toshimori H, Yamaguchi H, Enoki S, Nakatsuru K, Matsukura S. Two Cases of Secondary Central Diabetes Insipidus Associated with Hyperosmolar Diabetic Coma. Journal of the Japan Diabetes Society 35: 31-36, 1992.

15. Delhaye F, Vincent JL, Fery F, Pirotte B, Unger J. Extreme polyuria: decompensated diabetes mellitus and/or diabetes insipidus? Intensive Care Med 21: 515-521, 1995.

16. Yoshida K, Kajihara S, Motomura M, et al. A Case of Idiopathic Diabetes Inspidus Complicated by Diabetic Ketoacidosis. Journal of the Japan Diabetes Society 39: 919-923, 1996.

17. Inaba $\mathrm{H}$, Funahashi $\mathrm{T}$, Ariyasu $\mathrm{H}$, et al. Diabetic ketoacidosis in a patient with acromegaly and central diabetes insipidus treated with octreotide long-acting release. Diabetol Int 8: 237-242, 2017.

18. Takagi H, Hagiwara D, Handa T, et al. Diagnosis of central diabetes insipidus using a vasopressin radioimmunoassay during hypertonic saline infusion. Endocr J 67: 267-274, 2020.

19. Shibue K, Fujii T, Goto H, et al. Rapid exacerbation of lymphocytic infundibuloneurohypophysitis. Medicine 96: e6034, 2017.

20. Vitelli A, Apuzzi V, Calderaro F Sr, Fattoruso O, Bassi V. A Triad of Ketoacidosis, Hypertriglyceridemia, and Acute Pancreatitis Associated With Sugar-Sweetened Soft Drinks Abuse in a Caucasian Patient With Undiagnosed Type 2 Diabetes Mellitus. Cureus 12: e 8299, 2020.

21. Reghina AD, Craciun S, Fica S. Severe Transient Hyperglycemia in a Prediabetic Patient during Mild Acute Pancreatitis. Case Rep Med 2015: 968593, 2015.

22. Imura H, Nakao K, Shimatsu A, et al. Lymphocytic infundibuloneurohypophysitis as a cause of central diabetes insipidus. $\mathrm{N}$ Engl J Med 329: 683-689, 1993.

23. De Bellis A, Colao A, Di Salle F, et al. A longitudinal study of vasopressin cell antibodies, posterior pituitary function, and magnetic resonance imaging evaluations in subclinical autoimmune central diabetes insipidus. J Clin Endocrinol Metab 84: 3047-3051, 1999.

24. Pivonello R, De Bellis A, Faggiano A, et al. Central diabetes insipidus and autoimmunity: relationship between the occurrence of antibodies to arginine vasopressin-secreting cells and clinical, immunological, and radiological features in a large cohort of patients with central diabetes insipidus of known and unknown etiology. $\mathrm{J}$ Clin Endocrinol Metab 88: 1629-1636, 2003.

25. Caturegli P, Iwama S. From Japan with love: another tessera in the hypophysitis mosaic. J Clin Endocrinol Metab 98: 1865-1868, 2013.

26. Yasuda Y, Iwama S, Kiyota A, et al. Critical role of rabphilin-3A in the pathophysiology of experimental lymphocytic neurohypophysitis. J Pathol 244: 469-478, 2018.

The Internal Medicine is an Open Access journal distributed under the Creative Commons Attribution-NonCommercial-NoDerivatives 4.0 International License. To view the details of this license, please visit (https://creativecommons.org/licenses/ by-nc-nd/4.0/).

(C) The Japanese Society of Internal Medicine Intern Med Advance Publication 